\title{
Reviewing imagery in resemblance and non-resemblance metaphors
}

\author{
JOSÉ MANUEL UREÑA and PAMELA FABER*
}

Abstract

This article analyses the nature of mental imagery in metaphoric thought as envisaged by the contemporary theory of metaphor in Cognitive Linguistics (Lakoff 1993). Our study of metaphor in the field of marine biology draws on two crucial aspects of mental imagery, namely dynamicity and pervasiveness. Image metaphors and behaviour-based metaphors have generally been regarded as two different types of resemblance metaphor. In our view, the dynamicity of certain mental images highlights inherent similarities between these two types of metaphor, and makes the differences between them more apparent than real. For this reason, we propose a more refined description of resemblance metaphors in terms of the static or dynamic nature of the mental images underlying them. Our study also underlines the fact that mental images permeate all classes of metaphor, and that the pervasiveness and dynamicity of mental images affords insights into both resemblance metaphors and non-resemblance metaphors.

Keywords: mental imagery; metaphor; dynamicity; marine biology; cognitive linguistics.

\section{Introduction}

Conceptual Metaphor Theory and Primary Metaphor Theory establish a sharp distinction between metaphors that arise from physical or behavioural analogy and metaphors motivated by abstract or subjective cognitive processes. In the case of Conceptual Metaphor Theory, Lakoff (1993)

* Correspondence address: University of Granada, Buensuceso Street 11, Postcode 18002, Granada, Spain. Tel.: (+34) 958 240517. E-mails:〈jmurena@ugr.es〉; 〈pfaber@ugr.es〉. 
and Lakoff and Turner (1989) distinguish between conceptual-structural/ conventional metaphors and image metaphors. However, Grady's (1997, 1999) Primary Metaphor Theory distinguishes between correlation metaphors and resemblance metaphors. These classes of metaphor arise by virtue of our embodied conceptualisation system.

In this article, we use the term resemblance metaphor to refer to image metaphors and behaviour-based metaphors, and non-resemblance metaphor to refer to conceptual/conventional metaphor and correlation metaphor. We prefer the term non-resemblance metaphor for three reasons. Firstly, it encompasses any type of metaphor that does not arise from resemblance. Secondly, the term conceptual metaphor is not felicitous because resemblance metaphors are also conceptual, as underlined in other studies (Kövecses 2002; Alexiev 2005). Thirdly, the term conventional metaphor is not a good choice because resemblance metaphors are also conventional.

According to Grady's (1999) characterisation of resemblance metaphors, image metaphors are associated with motionless visual images, whose motivation for metaphorical transfer is based on physical properties (e.g., shape and colour). In contrast, there are other metaphors that result from behavioural comparison, and therefore, are typically linked to motion and dynamicity.

This article challenges this classification. Our study of resemblance metaphor in the field of marine biology indicates that image metaphors and behaviour-based metaphors are closely linked. In fact, what truly differentiates these metaphors is the static or dynamic nature of their underlying images ${ }^{1}$. Rather than belonging to two different categories, they should be regarded as belonging to a graded category in which members differ in terms of the dynamicity of their images. As shall be seen, imagery is also important in non-resemblance metaphors. This means that images and their analysis should go far beyond mere physical or behavioural resemblance.

\section{Defining imagery}

Imagery has two related senses. First of all, it refers to quasi-perceptual experience, which significantly resembles perceptual experience, but oc-

1. In this regard, this research work is on a par with other studies. For instance, Caballero (2006) explores a host of image metaphors that are dynamic, and Peña (2003) makes a distinction between situational and non-situational metaphors that is based on the feature of dynamicity. 
curs in the absence of the appropriate perceptual stimuli (Thomas 1999: 208). This definition includes image schemas and mental images, both of which are key ideas in Cognitive Linguistics (cf. Johnson 1987; Lakoff and Johnson 1999).

An image schema can be regarded as an instance of imagery simpliciter or 'an especially 'unsaturated' form of imagery, produced by simulating only the very earliest and most generally applicable stages of the process of a perceptual exploration" (Thomas 2009, A note on "schema" and "image schema", para. 9). Apart from being an unsaturated form of imagery, they are non-intentional because they do not participate in the conscious act of perceiving. In other words, image schemas are emergent properties of unreflective bodily experience (Gibbs and Colston 2006: 247).

In contrast, a mental image is a more substantiated kind of mental representation. It cross-cuts any sensory mode, and embodies our perceptual and imagistic awareness ${ }^{2}$. Mental images are intentional, insofar as they involve a conscious mental act of perceiving. In other words, they are the result of more effortful cognitive processes (Gibbs and Colston 2006: 247).

Mental images also have content specificity, the complexity of which is constrained by linguistic and environmental situatedness. Image schemas may also be complex, but in the sense that they can combine to give structure to conceptual domains (cf. Cienki 1997: 9; Kimmel 2005). This structure entails conceptual relationships, and accordingly, it has been shown that some image schemas are subsidiary or subordinate to others (Peña 1999).

The second sense of imagery is related to a well-entrenched view in cognitive psychology that mental images are a key factor in creative thought (cf. Finke et al. 1992; Weisberg 1986). Consequently, imagery not only refers to true imagination, but also to the production of mental images that arise from our capacity to separate, shuffle, distort and recombine simpler mental images in the first sense. This ability has its cognitive uses

2. The notion of "mental image" is admittedly rather vague. Because of this, a mental image need not refer to a "mental picture", but can also refer to sensory images or image simulations in different sensory modes. As Pylyshyn (2003: 113) aptly points out, this is due to the fact that "neither language nor pictures are sufficient to represent the content of thought and that most thought is not available to conscious inspection [...] If there is something special about the format in which we think when we have the experience of 'seeing with the mind's eye', nobody has satisfactorily articulated what it is". 


\section{Author's Copy}

(Finke et al. 1989; Finke et al. 1992), including the generation of metaphoric thought.

In our view, both senses of imagery are essential to account for mental images in metaphoric thought.

\section{Image metaphors and behaviour-based metaphors}

Grady (1999), Lakoff (1993), and Lakoff and Turner (1989) agree that the core feature of image metaphors is the comparison between the images of two entities. Lakoff (1993: 230) writes that because two images are being compared, these metaphors are called image metaphors:

Metaphoric image-mappings work in just the same way as all other metaphoric mappings: by mapping the structure of one domain onto the structure of another. But here, the domains are conventional mental images.

The prototypical conception of an image metaphor is a metaphor based on resemblance in shape and/or colour. In this way, clear instances of marine biology image metaphors are seahorse (Hippocampus), which refers to a fish with a horse-like head (see picture in Table 1 in the Appendix), and milkfish (Chanos chanos) because of the white underside of this fish (see picture in Table 1 in the Appendix). These metaphors are based on visual perception, which is the dominant component of our embodied conceptualisation system (Watt 1991). For this reason, this type of metaphor has the highest degree of iconicity or mental imagery shared by the source and target concepts. These metaphors clearly differ from behaviour-based metaphors, such as hermitcrab (Paguroidea) in which the crab acts like a hermit instead of looking like one.

According to Grady (1999), behaviour-based metaphors cannot be called image metaphors because they are based on behavioural rather than physical resemblance. By way of example, Grady (1999: 89) mentions the well-known metaphor Achilles is a lion. Since Achilles' courageous actions resemble the aggressive behaviour of lions without any claim about his physical appearance, this metaphor cannot be considered an image metaphor.

Strictly speaking, according to Grady's classification, marine biology terms such as sea nettle, archerfish or triggerfish are not image metaphors either, since they are based on behavioural or functional resemblance. Nevertheless, we argue that these metaphors also evoke mental images, and that mental images are not exclusively associated with metaphors based on physical comparison. 


\subsection{Images in behaviour-based metaphors}

There is a growing body of research in cognitive psychology showing that mental representations of perceptual experience are central to cognition (cf. Damasio 1994; Finke 1989; Paivio 1971, 1986; Thomas 1999³). In this section we show that behaviour-based metaphors are grounded in mental images that can be either dynamic or static.

3.1.1. Dynamic images in behaviour-based metaphors. Behaviour-based metaphors, such as Achilles is a lion, emerge from the visual experience of a motor action, which yields a set of images that are fleshed out by spatial-dynamic actions. In this metaphor, we evoke images of Achilles bravely confronting his enemies and a lion fiercely fighting other animals for survival (also in Ruiz de Mendoza and Peña 2008). The nature of these images is constrained by the image-schematic topology of the target domain, which cannot be violated by the cognitive topology of the source domain, while still remaining consistent with it. This is in consonance with Lakoff's Invariance Principle (Lakoff 1990, 1993). In spite of this constraint, the images retrieved by this type of metaphor are disperse since each individual may re-create these actions in different mental scenarios. As Deane (2005: 247) points out, "the same spatial relation may receive distinct representations in multiple representational modalities".

Although most research on imagery in contemporary cognitive psychology focuses on visual perception (and, to a much lesser extent, on audition), there is growing evidence that kinaesthetic, somaesthetic and haptic perception is also pivotal to mental image formation (cf. Gibbs 2006; Gibbs et al. 1994; Gibbs and Colston 2006 [1995]; Popova 2005). This means that mental images need not necessarily be visual in nature, and that visual imagery and kinaesthetic imagery "share a common representational, and possibly neuropsychological substrate" (Gibbs 2006: 124).

According to Paivio's $(1971,1986)$ dual coding approach, cognitive tasks are mediated not only by linguistic processes, but also by a nonverbal imagery model of thought as well. What Paivio calls the image system in our brains refers to both non-verbal objects and events, and arises not only from visual stimuli, but also from auditory, kinesthetic, and other

3. Thomas (1999) dwells on the three major theories of imagery in Conceptual Science, namely Picture Theory, Description or Propositional Theory, and Perceptual Activity Theory. He aligns himself with Perceptual Activity Theory, according to which "perceptual learning is not viewed as a matter of storing descriptions (or pictures) of perceived scenes or objects, but as the continual updating and refining of procedures or schemata" (Thomas 1999: 218). 


\section{Author's Copy}

sensory components of non-verbal information. Accordingly, behaviourbased and function-based metaphors can also be regarded as image metaphors because they are closely linked to conventional mental images representing events, which are not necessarily based on visual stimuli. Moreover, since behaviour and function mostly involve (loco)motion on account of a correlation or cause-effect event, most behaviour-based images (i.e., images that feature the behaviour of a living being) and function-based images (i.e., images that feature the functioning of an instrument, device or machine) are unquestionably dynamic.

3.1.1.1. Sea wasp. In the field of marine biology, many specialised concepts have basic-level category denominations. This guarantees richly contoured and easily retrievable mental images, since the basic level is the level of rich mental images and rich knowledge structure (Lakoff 1993: 212). For example, the metaphor sea wasp, which is an alternative scientific name for jellyfish Chironex fleckeri (see picture in Table 1 in the Appendix), evokes an easily retrievable image that primes kinaesthetic perception. It also gives priority to the more subjective sensory image of actually participating in an event, rather than to the objective and visual pattern of observing it. In this case, the perceptual experience foregrounded is touch, which is a somaesthetic and kinaesthetic sense, and like vision, also a spatial sense (Popova 2005: 402).

This metaphor evokes the dynamic event image of our touching a wasp, its stinging us, and our subsequent experience of pain. This image is mapped or superimposed onto the image of a jellyfish injecting its stinging capsules or nematocysts under our skin, which causes the pain.

This metaphor has a metonymic basis. The close relationship and interaction between metaphor and metonymy has been underlined in recent research (cf. Barcelona 2003; Radden 2002). More precisely, the sea wasp metaphor is based on two conceptual metonymies operating on the two domains or categories connected by the metaphor. In the metonymies, the source is the STINGING CAPACITY, which is a shared attribute of the targets WASP and JELLYFISH. In other words, both wasps and this type of fish have to be metonymically understood from their salient property sTiNGING CAPACITY as metonymic source, which creates the abstract similarity that makes the metaphorical connection between the source (WASP) and the target (JELLYFISH).

3.1.1.2. Archerfish. Another example of a behaviour-based metaphor relying on dynamic images is archerfish (Toxotidae). The behaviour of this fish is compared to that of an archer, which includes the function of an archer's bow, which shoots arrows at a target. The reason for this 
comparison is that archerfish have the ability to spit water droplets at aerial insects (either on the wing or resting on surfaces above the water), and thus knock them onto the water to be eaten (see picture in Table 1 in the Appendix). Thus, the dynamic image of an archer shooting an arrow at his target is superimposed onto the image of an archerfish spitting water at an insect. This metaphor also has a metonymic basis. The source domain of the metonymies is SHOOTING CAPACITY as instantiated by: (i) the archer's use of a bow and arrow; (ii) the archerfish's projection of water droplets to hit insects. The source domain of the metonymies stands for the targets, ARCHER and ARCHERFISH, and is in turn responsible for the abstract similarity that makes the metaphorical connection between the source (ARCHER) and the target (ARCHERFISH).

All of these metaphors can also be approached from the perspective of Conceptual Blending Theory (Fauconnier and Turner 1998, 2002). They are clear instances of formal blending, more specifically, of compounding. For example, archerfish involves two input spaces relating to archer and fish, plus the conventional array of meanings linked to these lexical items. However, the projection to the blended space is selective, including only the subset of semantic features associated with the concepts of both archer and fish, along with their forms (i.e., word projection). Thus, both conceptual structure and linguistic structure are projected onto the blend, giving rise to a new emergent structure. Figure 1 illustrates this scenario.

This structure is novel both from a linguistic point of view (the creation of a new word) and from a semantic point of view (the creation of a new meaning).

3.1.2. Static images in behaviour-based metaphors. Although behaviour most frequently implies dynamic mental images, curiously enough, we have found behaviour-based metaphors in the field of marine biology that are based on static images.

For instance, the metaphor hawkfish (Cirrhitidae) refers to a fish that behaves like a hawk because it rests atop the highest point on the coral reefs, waiting for suitable prey to appear (see Table 1 in the Appendix). The fish then dives down to capture its prey. The initial image of a motionless hawkfish awaiting its prey on a high vantage point maps onto that of a motionless hawk on a tree branch or cliff, waiting to capture its prey.

Still another example is the metaphor garden eel (Heterocongridae). Garden eels receive this name because they live in colonies, keeping the main portion of their bodies buried in the sandy sea bottom while the rest remains upright in the open sea (see Table 2 in the Appendix). This behaviour retrieves a motionless image which resembles that of slim 


\section{Author's Copy}

Input Space Archer

Input Space Fish

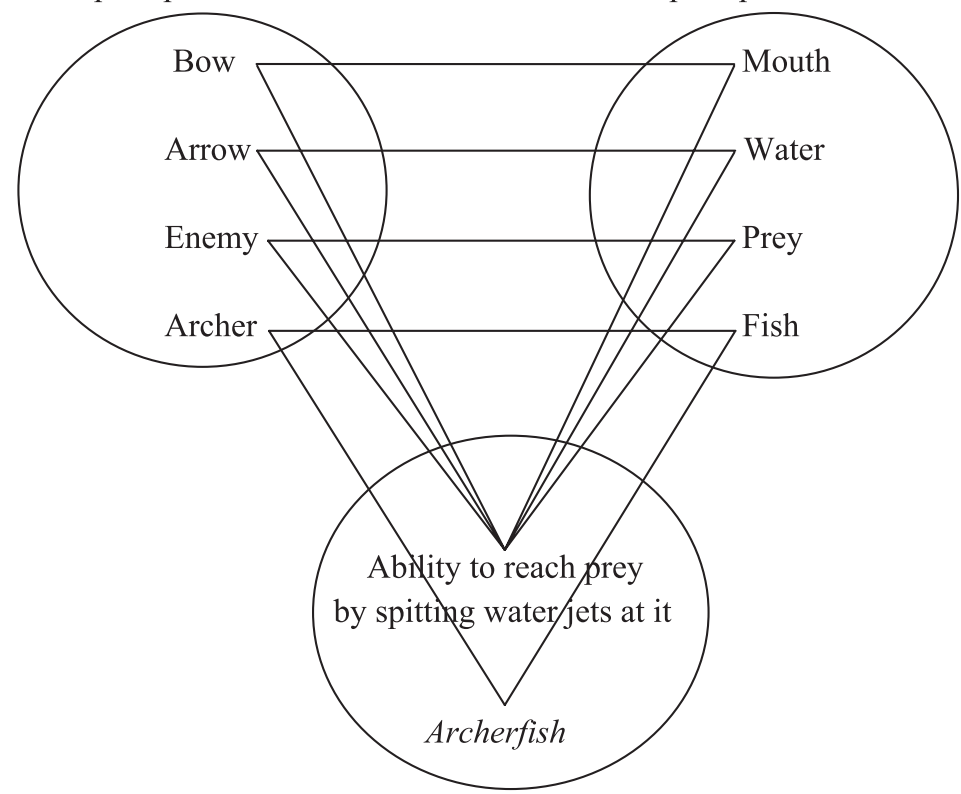

Blended Space Archerfish

Figure 1. Blended space of archerfish

plants in a garden. The garden eel metaphor also entails a physical aspect motivation: the mass-effect shape of the eels allows for the comparison between these animals and a garden. On this basis, we argue that this is another metonymy-based metaphor. The source of the metonymies, i.e., the STATE OF STANDING STILL, maps onto the targets, i.e., PLANTS IN THE GARDEN and EEL, and prompts the metaphorical connection between them.

\subsection{Dynamic image metaphors}

In marine biology, most of the examples refer to either a behavioural/ functional model or a physical-aspect model. For instance, the metaphors sea nettle and sea wasp are based on behaviour. Archerfish integrates behavioural and functional motivations, whereas triggerfish arises from resemblance in function. Independently, horseshoe crab is a shape-induced metaphor, and sea lettuce emerges as a result of comparison in shape and colour (see Table 1 in the Appendix). 
Generally speaking, we tend to think of shape and colour as more static than dynamic attributes. However, it is evident that an entity can change its shape as well as its colour. Accordingly, there are also dynamic metaphors based on physical comparison. This fact supports the claim that "people find it easier to make sense of [...] moving objects over those that are stationary" (Gibbs and Colston 2006: 252). Concerning shape, Deane (2005: 249-250) affirms that "there are multiple representations of shape: one representation depicts static forms; the other depicts dynamic form". Lakoff (1993: 229) provides the following example when describing the characteristics of image metaphors: "the image of the slow, sinuous walk of an Indian woman is mapped onto the image of the slow, sinuous, shimmering flow of a river'. Though involving dynamicity, this example features an image metaphor because it is moving shapes or lines that are compared.

However, dynamism also entails behavioural or functional patterns. These are processed in our brains, and create interrelated experiencebased concepts that become meaningful because of these regular patterns. This evidently leads to behaviour-based or function-based metaphors. Thereby, the slow and sinuous walk of the Indian woman is part of the way she walks, and thus, of her behaviour. Likewise, the slow and sinuous flow of a river is also part of its behaviour. Thus, this is a resemblance metaphor which integrates physical and behavioural motivations.

There are also resemblance metaphors in marine biology that combine both behaviour and physical appearance. Such is the case of the anglerfish (Lophius). This fish behaves like, and thus, resembles an angler for two reasons: (i) the shape of the foremost spine of its dorsal fin looks like a fishing rod with its fishing line and fleshy bait at its tip (see picture in Table 2 in the Appendix); (ii) this spinal fishing rod is used as a lure for attracting prey which stray close enough for the anglerfish to swallow. Since catching a prey is an action or event, this can be regarded as a dynamic image.

Still another example is the metaphor boxer crab (Lybia tessellata). This crab holds an anemone in each pincer, and uses these anemones for protection (usually against octopuses) in the same way as a boxer uses his fists against his opponent (see picture in Table 2 in the Appendix). These little round-shaped anemones resemble boxing gloves, while the action of attacking predators with the anemones is a type of behaviour that resembles that of a boxer.

Regarding colour, an example of a dynamic resemblance metaphor is chameleon fish (Badis badis). This is a freshwater fish that changes its skin colour when hungry, threatened or protecting its eggs, offspring, or territory (see pictures in Table 2 in the Appendix). This change of skin 


\section{Author's Copy}

colour occurs within a single static locus (i.e., locomotion is not involved). Yet, this type of effect creates mental video-clips of sequentially unfolding images, which naturally implies change or dynamic structure. This is the reason why we recruit the superimposed dynamic images of a real chameleon and of this fish, altering their skin colour. This physical ability is part of their behaviour.

In summary, image metaphors and behaviour-based metaphors are not clearly differentiated categories, since there is a group of metaphors that possess characteristics of both, and thus reside in a transition zone between the two.

\subsection{Fictive dynamicity in resemblance metaphors}

Our tendency to think in terms of dynamic patterns has been documented (cf. Talmy 1999 [1996]). Such tendency hinges upon representations that are motionless in nature. These representations emerge from what Talmy (1999 [1996]: 245) calls ception or fictive motion, which involves "sensory stimulation, mental imagery, and ongoingly experienced thought and affect".

Metaphor is found in fictive motion constructions dealing with spatial description (Talmy 1996). Regarding specialised language, Caballero (2006) identifies instances in architectural discourse where metaphor plays a role in fictive motion. Example (1) given by Caballero (2006: 180) includes motion verbs codifying actual static scenes, which are conceptualised as non-veridical dynamic images through metaphorisation:

(1) Based on a boomerang shaped plan, the new building steps down from a prow at its south end to embrace a new public space.

In the field of marine biology, we have also found metaphorically extended motion verbs that evoke visual mental images involving fictive dynamic structure, as shown in the following examples:

(2) The Røst Reef, the world's largest known deep water coral reef, forms a structure that fades away to depths between 300 and $400 \mathrm{~m}$.

(3) The seaward edge of a reef is fairly steep and slopes down to deeper water. Since the water is generally clearer, corals may grow to the depths of $50 \mathrm{~m}$ depending on light available.

(4) In tile Pulmonate tile rudimentary velum, v, is marked by a line of granular ciliated cells, which [...] bends up towards the dorsal surface, in such a way as to almost encircle the tentacles.

These metaphors are clearly imagistic in nature, and form a part of the expert's visual thinking (Caballero 2006: 3). What makes this type of 
metaphors interesting is their complex nature. They can be regarded as instantiations of the more general metaphor FORM IS MOTION (Lakoff and Turner 1989: 142-144). At the same time, these metaphors emerge because the form that they evoke matches the actual shape of the entities, and is based on how they are visually scanned. In other words, despite the fact that they are often classified as non-resemblance metaphors, resemblance is involved here, but of a more sophisticated kind.

We can thus conclude that while the two types of resemblance metaphor cannot be regarded as clear-cut categories because dynamic structure and static structure permeate both categories, in some resemblance metaphors it is the boundaries between static structure and dynamic structure that are fuzzy. However, the fuzzy boundaries between both schemas in these resemblance metaphors answer psychological strategies rather than reflect the actual state of affairs. In short, the conceptualisation of factive statis or stationariness through this kind of metaphor is biased because it results in images involving fictive change.

\section{Non-resemblance metaphors}

Resemblance metaphors emerge from the superimposition of easily retrievable mental images. Yet, non-resemblance metaphors also involve the retrieval of mental images. Precisely, the great bulk of research on figurative mental imagery is currently on non-resemblance metaphors. Consequently, both types of metaphor are more closely linked than previously assumed. The pervasiveness of mental imagery is due to the logic of our embodied conceptual system, which licenses the creation of any type of metaphor on the basis of mental images. Therefore, strictly speaking, mental imagery constitutes the grounding of metaphoric thought.

\subsection{Mental images in non-resemblance metaphors}

Lakoff (1993: 229) writes that the rationale of conceptual metaphors, namely understanding abstract concepts through concepts directly grounded in bodily experience, involves mental imagery, which is the mental realisation of such experience:

Abstract reasoning is a special case of imaged-based reasoning. Image-based reasoning is fundamental and abstract reasoning is image-based reasoning under metaphorical projections to abstract domains.

As a general rule, words can designate portions of conventional mental images (Lakoff and Johnson 1999: 69). Recent research provides evidence 


\section{Author's Copy}

that language makes much greater use of the brain's mental imagery than previously thought (Rohrer 2005: 166). In keeping with the two-domainof-experience mapping system proposed by Conceptual Metaphor Theory, "when both domains are active, imagery associated with sourcedomain entities can be activated, and thereby associated with the targetdomain entities neurally connected to them" (Lakoff and Johnson 1999: 56).

As previously discussed, kinaesthetic perception involves motor activity or bodily (loco)motion, which occurs in space. In fact, mental imagery is prominent in the form of spatial-dynamic images, especially when it comes to real or imagined body action. As pointed out by Rohrer (2005: 169), "mental imagery can also be kinaesthetic, as in the felt sense of one's own body image". Mediation of the lived body action for mental image formation is called embodied simulation (Gallese 2005).

Gibbs and Perlman (2006: 223) affirm that "processing metaphoric meaning is not just a purely cognitive act, but involves some imaginative understanding of the body's role in structuring abstract concepts". Examples of embodied simulation can be found in expressions such as chewing on the idea and grasping an idea, which arise from the conceptual metaphor IDEAS ARE OBJECTS. Gibbs et al. (2006) demonstrated that people imaginatively engage in the act of chewing or grasping something to better understand these metaphorical phrases. Furthermore, it has been shown that the literal re-enactment of figurative verbal cues activates the primary motor and somatosensory cortices in our brains (Rohrer 2005). This underscores the significance of embodiment or sensorimotor experience for metaphorical concept formation.

Since Conceptual Metaphor Theory posits that abstract concepts are ultimately grounded in perceptual or bodily grounded experience (Kövecses 2005; Lakoff 1990; Lakoff and Johnson 1980), mental imagery is thus an integral part of all metaphors. As Caballero (2003a: 152) stresses in the field of architecture, if a distinction is to be made between images and concepts, such a distinction should not lie in the image component, since all the information organised and processed in our minds is essentially imagistic. In a like way, it can also be argued that all the information organised and processed in our minds, including images, is also conceptual.

Mental images are likewise present in an extensive class of metaphorical or imageable idioms (Lakoff 1987; Lakoff and Johnson 1999). An imageable idiom comes "with a conventional rich mental image and knowledge about that image" (Lakoff and Johnson 1999: 68). According to Lakoff and Johnson (1999), a significant portion of the array of linguistic expressions stemming from the conceptual metaphor LOVE IS A JOURNEY 
consists of idioms. They give the expression spinning one's wheels as an example.

In marine biology we have also found non-resemblance metaphors based on dynamic mental images. This is the case of recruitment, which refers to the incorporation of new members of one species to the stock of the already existing individuals, particularly those living in communities. This includes shoals of fish and planktonic aggregates. This metaphor can be subsumed by the more general metaphor MARINE COMMUNITIES ARE MILITARY STRUCTURES, which gives rise to metaphorical terms, such as intrusion, cohort, sentinel organism, invasive exotic species, evolutionary arms race and line of defence. Recruitment activates the generic dynamic mental image of a group of organisms that increases as new organisms join them. The specific details of this image largely depend on the context in which the metaphor is embedded. For instance, the recruitment of individuals of the species Engraulis encrasicolus, which is a type of anchovy, evokes a different mental image from that evoked by the recruitment of individuals of the species Labidocera scotti, a kind of marine planktonic copepod (i.e., a small crustacean).

A second factor constraining and modelling the mental image activated is encyclopaedic meaning. According to Lakoff and Johnson (1999: 69), a metaphorical word "is not just a linguistic expression of a metaphorical mapping, but the linguistic expression of an image plus knowledge about the image plus one or more metaphorical mappings". Thus, the mental image of the recruitment of anchovies evoked by an expert in marine biology is certainly richer than that evoked by a layman. However, it is also true that cognitive patterns give priority to the objective aspects of images rather than to their subjective implications (Dewell 2005: 386).

Moreover, culture, as a specific type of contextual factor, also has a decisive role in forming conventional rich images, which "appear to be pretty much the same from person to person in the same culture" (Lakoff 1987: 450). However, when cultures differ, so do images. Consequently, when a European biologist builds a mental image of the recruitment of anchovies, in all likelihood the image brought to mind is that of an anchovy of the species Engraulis encrasicolus, most frequently found in the Mediterranean Sea. The physical features of this species of anchovy are different from those of the species Encrasicholina heterolobus, which inhabits the Indo-Pacific region. A biologist from Australia would probably activate an image of this species of anchovy, when he or she is thinking about recruitment.

It can thus be concluded that mental images permeate both resemblance metaphors and non-resemblance metaphors. 


\section{Author's Copy}

\subsection{Similarities between non-resemblance metaphors and resemblance metaphors}

The previous section showed that mental images, traditionally associated with resemblance metaphors, have an important role in non-resemblance metaphors as well. In this section we argue that resemblance metaphors also have features that are traditionally considered to pertain exclusively to non-resemblance metaphors.

Conceptual Metaphor Theory has primarily focused on conceptual/ conventional metaphors, which emerge from multiple mappings between two content-rich domains of experience. In other words, they have "rich knowledge and rich inferential structure" (Lakoff and Turner 1989: 91). Although this work is of undeniable interest, it has also meant that image metaphor has been more or less left out in the cold, and has been regarded as a kind of second-class metaphor. The main reason for this is that image metaphor is regarded by Lakoff and co-workers as a fleeting, ad hoc kind of metaphor with an impoverished inner structure (Lakoff 1987, 1993; Lakoff and Turner 1989).

Nevertheless, in recent years there has been a renewed interest in resemblance metaphor. Corpus-based research both in general language (Deignan 2007) and specialised discourse (Caballero 2003a, b, 2006 in architecture) shows that resemblance metaphors are well-established, conventional metaphors that arise from enduring and productive patterns of figurative thought.

For example, our research in marine biology shows that certain wellentrenched resemblance metaphors can be brought together under productive, encompassing metaphors. Accordingly, terms like elephant seal (Mirounga), seahorse (Hippocampus), sea lion (Otariidae), hawkfish (Cirrhitidae), spider crab (Maiidae), boarfish (Capros aper) and sand tiger shark (Carcharias taurus) can be subsumed by the general metaphor SEA ANIMALS ARE LAND ANIMALS.

Another such metaphor is MARINE ORGANISMS ARE WORKERS, which stems from the multiple-correspondence process involving metaphorical terms, such as surgeonfish (Acanthuridae), pilot fish (Naucrates ductor), anglerfish (Lophius), fiddler crab (Uca), harvestfish (Peprilus alepidotus), by-the wind sailor (Velella spirans), nurse shark (Ginglymostoma cirratum), innkeeper worm (Urechis), and rock cook (Centrolabrus exoletus) ${ }^{4}$.

Still another aspect that places resemblance metaphors on the same level as non-resemblance metaphors is that resemblance metaphors

4. As shown in Section 3.3, the resemblance metaphors involving fictive dynamicity can also be subsumed by a more general metaphor (i.e., FORM IS MOTION). 
meet the two generalisation principles proposed by Lakoff (1993: 209) for non-resemblance metaphors, namely, the polysemy generalisation and the inferential generalisation. According to the polysemy generalisation, certain linguistic expressions of the source domain acquire related senses.

For example, terms like thresher, and sponge have two or more senses, one of which refers to marine organisms. The main sense of thresher refers to a man who threshes the grain by beating it with a flail (a long, thin tool). In marine biology, a thresher is a shark of the genus Alopias. The metaphorical motivation is resemblance in both shape and behaviour. Regarding shape, the shark's abnormally long, thin, caudal fin looks like a flail, and insofar as behaviour is concerned, the shark uses its flaillike fin to strike its preys and render them dazed.

In the case of sponge, the central meaning of the concept is the marine biology sense. Sponge refers to a marine invertebrate animal of the phylum Porifera, characteristically having a porous skeleton composed of fibrous material or siliceous or calcareous spicules. The metaphoric sense of sponge, namely, porous plastics, rubber, cellulose, or other material chiefly used for washing, bathing, and cleaning, arises on account of physical resemblance because the porous structure of this object looks like the skeleton of the marine organism.

By virtue of the inferential generalisation, "each mapping defines an open-ended class of potential correspondences across inference patterns" (Lakoff 1993: 10). This is true for metaphors in the domain of marine biology because new species are continually being discovered. Such species are usually given metaphorical names that fit into existing metaphorical systems within the domain, and thus increase the number of cross-domain correspondences and mappings that characterise a given resemblance metaphor. This capacity to infer, which emerges from the topological or gestaltic structure of conceptual (as opposed to linguistic) metaphors (Lakoff and Johnson 1980), follows a robust domain logic to create terms for marine organisms, as well as other terms.

Accordingly, surgeonfish have scalpels; anglerfish use their baits; harvestfish harvest food for survival; pilotfish usually travel together with sharks (see picture in Table 1 in the Appendix); and a burrow of innkeeper worms is occupied by several commensals. These examples clearly reflect the role played by visually biased figurative language as an efficient instrument to organise thought through prolific inferential processes and evaluation (Caballero 2006: 3). More concretely, these examples show the importance of visual thinking in the creation of conceptually rich domain knowledge, which is enhanced by the high number of systematic crossdomain correspondences. 


\section{Author's Copy}

\section{J. M. Ureña and P. Faber}

In this respect, the difference between both classes of metaphors lies in the type and nature of mappings involved since both have multiple mappings as well as polysemic and inferential conditions.

\subsection{Mental images in primary metaphors and correlation metaphors}

Grady (1999: 87) clearly highlights the role of imagery in primary metaphors:

Quantity, desire [...] may take place at the level of cognition whose operation is not directly accessible to consciousness. In order to manipulate them at the conscious level it may be necessary to tie these elements of mental experience to specific sensory images.

Grady (1997: 100) affirms that the direct bodily basis of primary source concepts is processed in our brains in the form of images (image content), which are paired with target concepts (response content) to build primary scenes. Although he states that primary scenes are not necessarily fleshed out by rich content, at the same time, he holds that primary scenes are local structures, motivated by particular moments in our experience. He thus argues for the participation of down-to-earth conceptual structure in the source domain that cannot be as abstract as image schemas ${ }^{5}$. This conceptual structure would therefore have a greater level of specificity than image schemas, and illustrate the need of our cognitive system to resort to more or less specific images when constructing (metaphoric) meaning. Grady's view is likewise endorsed by Lima (2006: 115):

For instance, all cases of containers can be included in the image schema of a container, but each case may involve many primary scenes, such as (a) going into a room or (b) taking something out of a box, which can generate distinct metaphors. Even if we can have a schematic mental representation that is abstract enough to include all cases, the experiences that generate the metaphors do not seem to be the same in all of them. For example, in scene (a) going into a room, we experience going into spaces with certain characteristics and certain limits; in (b) taking something out of a box, we experience interacting with a container and its contents.

It could be argued that high-level primary metaphors such as ORGANISATION IS PHYSICAL STRUCTURE are not based on images of a specific type.

5. Far from criticizing image schemas, we are underlining the important role of images in metaphoric thought that is not resemblance-based. 
However, we should not forget that these are metaphoric formulations, namely, abstractions or generalisations of concrete linguistic and environmental situations. As research shows, language processing draws on location-specific perceptual images of entities and their attributes (Bergen et al. 2007: 734). Therefore, we can only have mental images of more or less specific types of physical structure (e.g., solids, liquids, etc.) if the abstraction is substantiated and situated. Evidently, the more information that we have about an entity, the richer its mental image will be. Moreover, "mental images are generated by assembling the parts of the image one part at a time" (Gibbs and Colston 2006: 247). In other words, we can speak of a procedural representation, in which the mental image of an entity is not built all at once, but rather sequentially by scanning its parts. It is our claim that mental images rather than solely image schemas are often the grounding for both resemblance metaphor and nonresemblance metaphors.

According to Grady (1997), primary metaphors involve experiential correlation, which consists of establishing a strong conceptual link between two distinct events that iteratively co-occur. This phenomenon usually gives rise to correlation metaphors because after repeated cooccurences in our experience of the world, we come to conceive one event in terms of another. This evidently makes correlation metaphors different from resemblance metaphors.

These basic correlation-induced physical experiences are generally recurring events throughout our life. For example, the experience of one's body moving through space generates the metaphor ACTIONS ARE SELFPROPELLED MOTIONS and expressions, such as I am moving right along on the project (Lakoff and Johnson 1999: 52). This expression is linked to the dynamic image of ourselves moving through space.

Since experiential correlation often implies a cause-effect event, it would seem that the retrieval of dynamic mental images for primary metaphors is at the center of this process. However, this is not always the case, because the range of sensorimotor domains activated in primary metaphors also includes static experiences, involving domains such as temperature (AFFECTION IS WARMTH), size (IMPORTANT IS BIG), physical configuration (UNINTERESTING IS FLAT) and location (STATES ARE LOCATIONS) ${ }^{6}$.

6. See Grady (1997) for an account of other primary metaphors, or Lakoff and Johnson (1999: 50-54), who also provide an inventory. 


\section{Author's Copy}

\subsection{Similarities and differences between correlation metaphors and resemblance metaphors}

In the field of marine biology, we have found resemblance metaphors based on cause-effect relationships, rather than physical similarity. The reliance on the cause-effect schema brings this type of resemblance metaphors close to correlation metaphors. In resemblance metaphors of this kind, the two entities involved share some facet of their behaviour or function (in the case of the source concept). In the case of the sea nettle, this property is a defence mechanism shared by both the plant and the marine organism. The experience involves a cause-effect experience of touching a nettle/sea nettle (cause/stimulus) and the subsequent perception of an itchy sensation (effect/response).

The example of the sea nettle is a cause-effect metaphor that highlights active (kinaesthetic) sensorial experience, i.e., direct interaction. However, there are also cases in which cause-effect events are backgrounded because passive (visual or auditory) experience is primed. For example, the term ghost crab, which is based on a resemblance metaphor, only implies the visual experience of a motor action. The ghost crab (Ocypode) receives its name because of its ability to disappear from sight almost instantly by sprinting and scuttling at speeds up to 10 miles per hour while making sharp directional changes. This crustacean behaves this way when it establishes visual contact with a potential predator (correlation or cause-effect event).

Consequently, marine biology resemblance metaphors could be classified in terms of the sensorimotor experiences that the terminological designations are based upon. The specification of the motivations for metaphorical transfer is essential for a clear classification of resemblance metaphors. Grady (1999: 98) acknowledges that an in-depth analysis is needed in order to further refine the different types of metaphor by carefully considering the motivations for these metaphors. This emphasises the significance of our embodied conceptualisation system, which licenses the formation of any type of metaphor on the basis of mental images, and involves all manner of sensorimotor experiences.

Cause-effect structure can also be at work in resemblance metaphors where behavioural comparison operates together with physical comparison. This is the case of the cookie-cutter shark (Isistius brasiliensis). This shark remains motionless at the sea bottom while its body emits a vivid, greenish phosphoresecent gleam, except for a black band around its throat. The prey of this shark is usually large fast-swimming fish. They are lured by what appears to be the silhouette of a small fish, which is actually the shark's non-luminiscent black collar. The shark behaves like 
a cookie-cutter in that once it has locked onto its lured prey (cause), the shark extracts cookie-shaped plugs of flesh (physical resemblance) from the victim (effect).

It should be noted that correlation in resemblance metaphors, while also entailing a cause-effect schema ${ }^{7}$, differs from correlation in primary metaphors in that in primary metaphors there is correlation between the source concept and the target concept, i.e., the source has a bearing on the target. Such source-target correlation does not exist in resemblance metaphor. For instance, in the sea nettle metaphor, the correlation between the hand touching the sea nettle (marine organism) or nettle (plant), and the resulting painful sensation is limited to either the source or the target. In other words, there is no co-occurrence of the events of touching the marine and the non-marine nettle, but only a resemblance between the overall cause-effect structure of source and target.

What occurs in resemblance metaphors of this kind is that the type of correlation operating in the source concept is mapped onto the target concept. This mapping is sanctioned by the nature of the experience, which is the motivation for the correlation in the target concept. Accordingly, the stinging plant is an appropriate source for the sea nettle because the former does not violate the conceptual topology of the latter (Invariance Principle), and both share their overall cause-effect structure. In this way, the source helps to activate relevant aspects of the target, and even allows the perceiver to infer other properties about it.

Still another difference between resemblance metaphors grounded in a cause-effect schema and correlation metaphors is the metonymic nature of the latter. The prototypical example which illustrates this claim is the MORE IS UP metaphor. Radden (2002: 414) writes:

In order to correlate two variables, they have to be conceptually contiguous. The correlation of quantity and verticality provides a perfect example of conceptual contiguity in that both variables originate from the same experiential basis.

Radden argues that the metonymic grounding of correlation metaphors is based on a continuum ranging from literalness via metonymy to metaphor. This process ties in with the notions of conflation and deconflation,

7. Correlation is not exclusively a matter of cause-effect links. In fact, Radden (2002: 414) argues that there are positive correlations, which tend to evoke a causal interpretation, and negative correlations, which do not invite a causal interpretation. However, in dealing with metaphor, we bind correlation to cause-effect structure because cause-effect correlation (i.e., positive correlation) is the only type of correlation that pertains to metaphor (Radden 2002: 414). 


\section{Author's Copy}

as well as the developmental model of primary scenes, which gives rise to primary metaphors (Grady 1997). The metaphor MORE IS UP comes into its own in four stages. The first stage involves UP being literally conceptualised. At the second stage, the variable or dimension quantity is conceptualised through partial metonymy (UP FOR UP). At the same time, quantity is linked to the dimension verticality by means of the experiential basis of conflation (i.e., UP + MORE). Conceptual conflation takes place in primary scenes, such as seeing the level of fluid in a container go up when more fluid is poured into it. As Radden (2002: 10) points out, the two manifestations of this highly frequent scene, rise of a level and rise of quantity, occur simultaneously and are intimately correlated. The third stage is deconflation, whereby UP and MORE become a full metonymy (i.e., UP FOR MORE). At the final stage of the continuum, this full metonymy becomes the primary metaphor MORE IS UP. Thus, it can be stated that the immediate basis of primary metaphors is metonymic in nature.

Radden (2002: 414) further states that the causal relation between quantity and verticality strengthens the metonymic basis of both these variables and licenses the reversibility principle of metonymic relationships, according to which "the flow of causation may be seen in either direction: 'something is more because its level is higher' or 'the level is higher because its quantity is more" ". In contrast, the pairs of cause-effect correlations that give rise to resemblance metaphors such as sea nettle occur independently (one pair in the source domain and another pair in the target domain). Therefore, they are not contiguous, which is the essential feature of metonymic mappings.

\section{Conclusions}

Within the category of resemblance metaphors there are certain very clear examples of image metaphors and behaviour-based metaphors. Prototypical image metaphors are based on visual stimuli in the form of static images. In contrast, prototypical behaviour-based metaphors are based on motion and dynamicity. However, other resemblance metaphors do not clearly belong to one category or the other. In our opinion, resemblance metaphor is a graded category, in which members are better or worse exemplars, based on the static or dynamic nature of the mental images underlying them. In other words, image metaphors and behaviour-based metaphors can be differentiated in terms of their degree of dynamicity. The existence of resemblance metaphors which combine behaviour and shape or colour seems to point to the need for a new, more refined classification. 
Evidence from specialised fields, such architecture and marine biology, shows that there is a more complex type of resemblance metaphors that are grounded in fictive dynamicity. Such dynamicity answers psychological strategies rather than reflects the actual state of affairs. In this case, it is the boundaries between static structure and dynamic structure that are fuzzy.

Recent corpus-based research shows that resemblance metaphors and non-resemblance metaphors share features, which up until now have been attributed exclusively to non-resemblance metaphor. The reason for this is the nature of mental imagery, which is an integral part of every stage of metaphor formation.

Received 10 December 2008

University of Granada

Revision received 9 September 2009

\section{Appendix}

Tables 1 and 2 show the marine biology resemblance metaphors referred to in this article. The metaphors in Table 1 represent separate, clear-cut categories, and are either image metaphors or behaviour/function-based metaphors. In contrast, Table 2 contains resemblance metaphors that are based both on behaviour/function and physical appearance. Pictures are provided to help understand the motivation for metaphorical transfer. 


\section{Author's Copy}

Table 1. Resemblance metaphors that are either image metaphors or behaviour/functionbased metaphors

\begin{tabular}{|l|l|l|l|}
\hline & $\begin{array}{l}\text { Metaphorical } \\
\text { term }\end{array}$ & $\begin{array}{l}\text { Type of } \\
\text { metaphorical } \\
\text { motivation }\end{array}$ & Picture \\
$\begin{array}{l}\text { Image metaphors } \\
\text { mental images) }\end{array}$ & Seahorse & Shape & \\
\cline { 2 - 4 } & Milkfish & Colour & \\
\hline & Sea lettuce & $\begin{array}{l}\text { Shape }+ \\
\text { colour }\end{array}$ & \\
\hline
\end{tabular}

8. Picture provided at www.divegallery.com/seahorse_page1.htm. Last access 21 May 2009.

9. Picture provided by Bryan Harry at http://www.nps.gov/archive/npsa/NPSAfish/ fish_pops/chanidae/milkfish01.htm. Last access 21 May 2009.

10. Picture provided by Guy Werner at http://home.vicnet.net.au/ earthcar/sgreport2. htm. Last access 21 May 2009. 


\section{Author's Copy}

Table 1 (Continued)

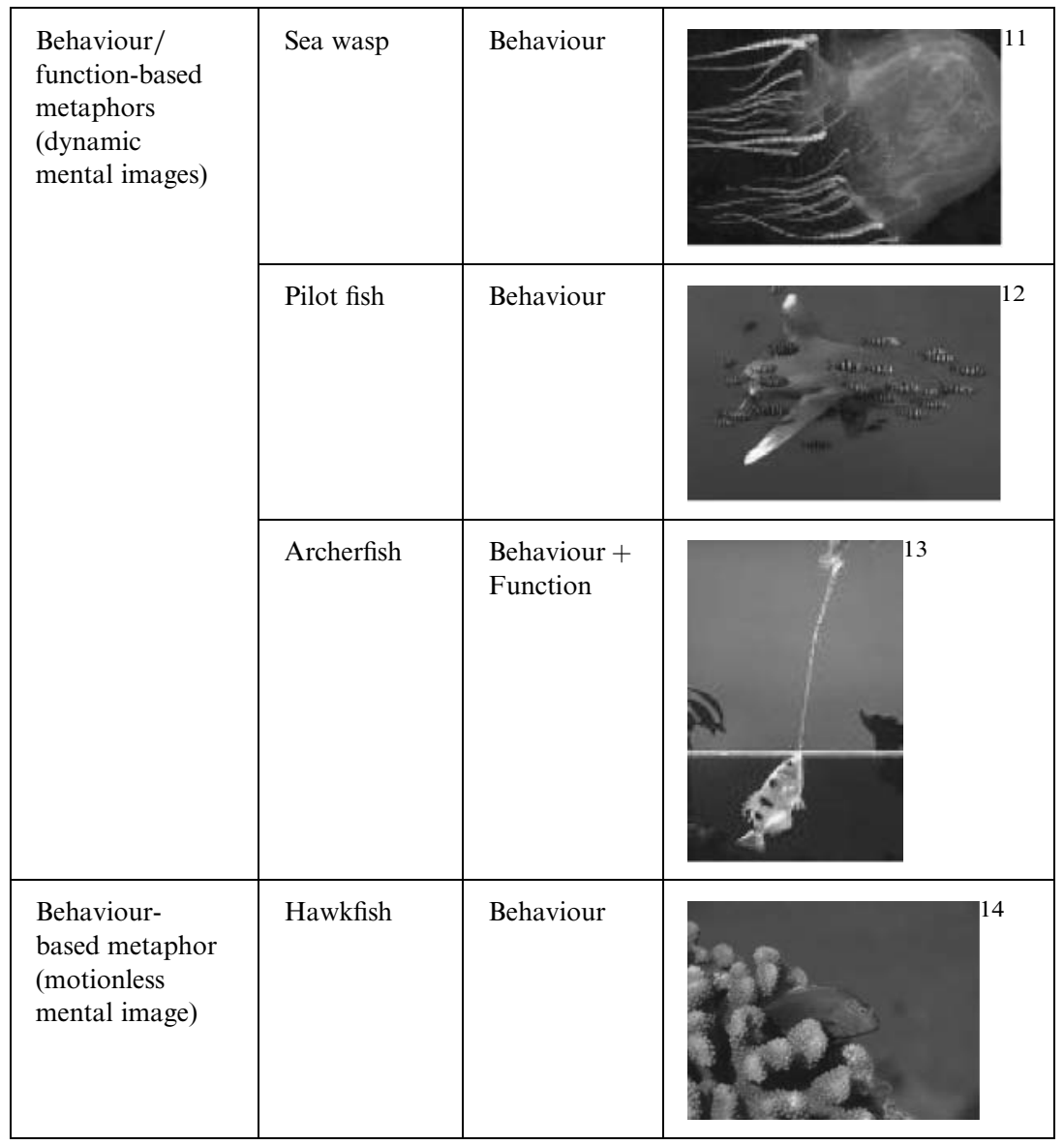

11. Picture provided by Dr. Zoltan Takacs at http://zoltantakacs.com/zt/pw/in/album. php?idx=18. Last access 21 May 2009.

12. Picture provided by Eric Orchin at http://photo.net/photodb/photo?photo_id =5270518. Last acces 21 May 2009.

13. Picture provided by Stefan Anitei at http://news.softpedia.com/images/news2/ Archerfish-Tunes-its-Shot-Power-to-the-Prey-Size-2.jpg. Last access 21 May 2009.

14. Picture provided by Mark Pidcoe at http://week.divebums.com/2006/Nov06-2006/ index.html. Last access 21 May 2009. 


\section{Author's Copy}

Table 2. Resemblance metaphors that can be regarded as both image metaphors and behaviour/function-based metaphors

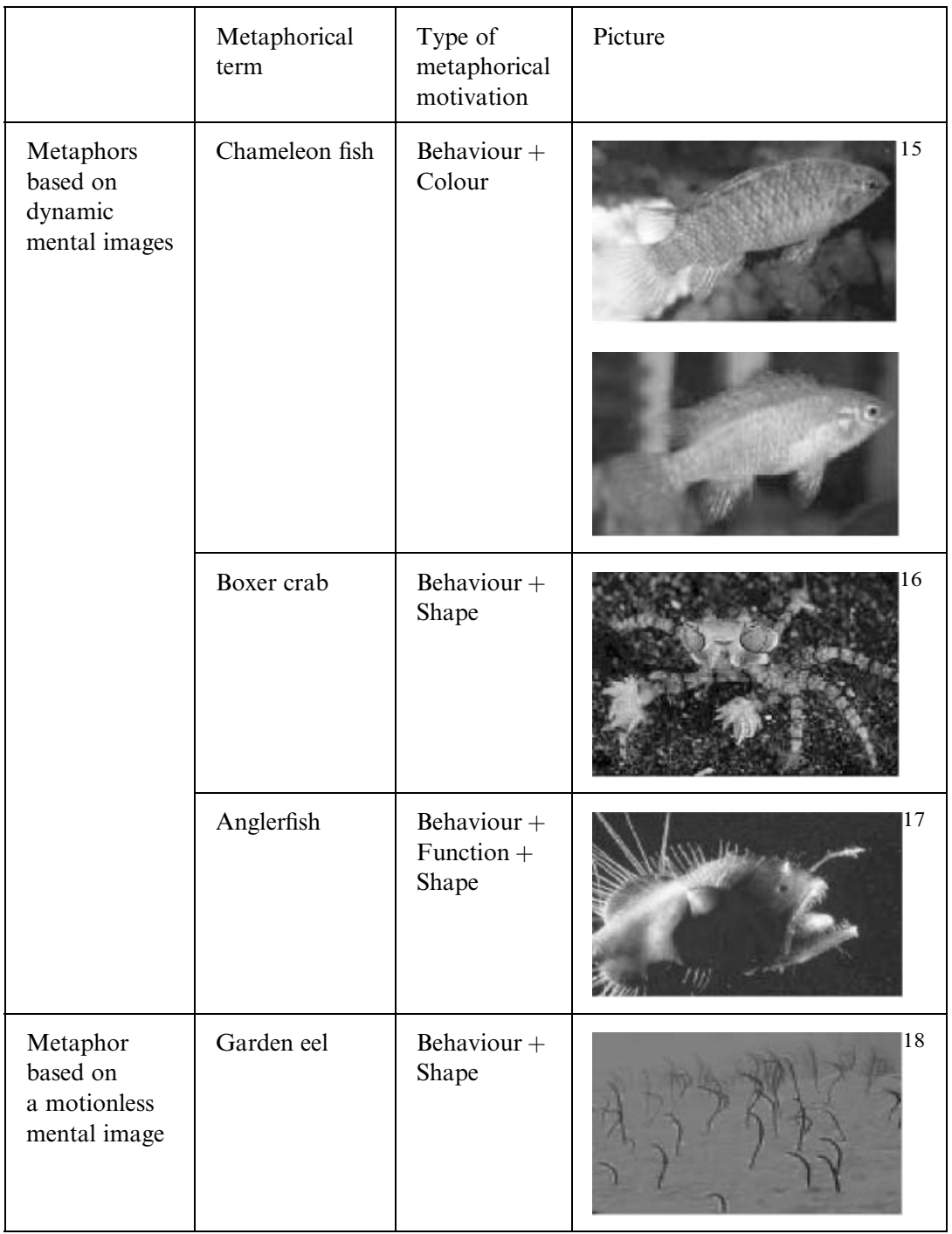

15. Pictures provided by LA Productions at http://aqualandpetsplus.com/Oddball, \%20Badis\%20badis.htm. Last access 21 May 2009.

16. Pictures provided by Linda Johnston at http://www.lembehresort.com/photo_image _pic_boxer_crab_by_linda_johnston_g8m38.html. Last access 21 May 2009.

17. Picture provided by Bruce Robison/Corbis at http://animals.nationalgeographic.com/ animals/fish/anglerfish.html. Last access 21 May 2009.

18. Picture provided by the Gull Dive Center at http://www.gullboatsandrv.com/index. aspx/Dive_Shop. Last access 21 May 2009. 


\section{References}

Alexiev, Boyan. 2005. Contrastive aspects of terminological metaphor. Sofia: University of Sofia PhD dissertation.

Barcelona, Antonio. 2003. On the plausibility of claiming a metonymic motivation for conceptual metaphor. In Antonio Barcelona (ed.), Metaphor and metonymy at the crossroads. Cognitive approaches, 31-58. Berlin \& New York: Mouton de Gruyter.

Bergen, Benjamin, Shane Lindsay, Teenie Matlock \& Srini Narayanan. 2007. Spatial and linguistic aspects of visual imagery in sentence comprehension. Cognitive Science 31. 733-764.

Caballero, María del Rosario. 2003a. Metaphor and genre: The presence and role of metaphor in the building review. Applied Linguistics 24. 145-167.

Caballero, María del Rosario. 2003b. How to talk shop through metaphor: Bringing metaphor research to the ESP classroom. English for Special Purposes Journal 22(2). 177-194.

Caballero, María del Rosario. 2006. Re-viewing space: Figurative language in architects' assessment of BuiltSpace. Berlin \& New York: Mouton de Gruyter.

Cienki, Alan. 1997. Some properties and groupings of image schemas. In Marjolijn Verspoor, Kee Dong Lee \& Eve Sweetser (eds.), Lexical and syntactical constructions and the construction of meaning, 3-15. Amsterdam: John Benjamins.

Damasio, Antonio. 1994. Descartes' error. Emotion, reason and the human brain. New York: Grosset/Putnam.

Deane, Paul. 2005. Multimodal spatial representation: On the semantic unity of over. In Beate Hampe (ed.), From perception to meaning. Image schemas in Cognitive Linguistics, 235-282. Berlin \& New York: Mouton de Gruyter.

Dewell, Robert. 2005. Dynamic patterns of CONTAINMENT. In Beate Hampe (ed.), From perception to meaning. Image schemas in Cognitive Linguistics, 370-393. Berlin \& New York: Mouton de Gruyter.

Deignan, Alice. 2007. Image metaphors and connotations in everyday language. Annual Review of Cognitive Linguistics 5. 173-191.

Fauconnier, Gilles \& Mark Turner. 1998. Conceptual integration networks. Cognitive Science 22(2). 133-187.

Fauconnier, Gilles \& Mark Turner. 2002. The way we think: Conceptual blending and the mind's hidden complexities. New York: Basic Books.

Finke, Ronald. 1989. Principles of mental imagery. Cambridge: MIT Press.

Finke, Ronald, Thomas Ward \& Steven Smith. 1992. Creative cognition: Theory, research, and applications. Cambridge: MIT Press.

Finke, Ronald, Steven Pinker \& Martha J. Farah. 1989. Reinterpreting visual patterns in mental imagery. Cognitive Science 13. 51-78.

Gallese, Vittorio. 2005. Embodied simulation: From neurons to phenomenal experience. Phenomenology and the Cognitive Sciences 4. 23-48.

Gibbs, Raymond W. Jr. 2006. Embodiment and Cognitive Science. New York: Cambridge University Press.

Gibbs, Raymond W. Jr., Dinara Beitel, Michael Harrington \& Paul Sanders. 1994. Taking a stand on the meaning of stand: Bodily experience as motivation for polysemy. Journal of Semantics 11. 231-251.

Gibbs, Raymond W. Jr. \& Herbert L. Colston. 2006. The cognitive psychological reality of image schemas and their transformations. In Dirk Geeraerts (ed.), Cognitive Linguistics: Basic Readings, 239-268. Berlin: Mouton de Gruyter.

Gibbs, Raymond W. Jr., Jessica J. Gould \& Michael Andric. 2006. Imagining metaphorical actions: Embodied simulations make the impossible plausible. Imagination, Cognition and Personality 25(3). 221-238. 


\section{Author's Copy}

Gibbs, Raymond W. Jr. \& Marcus Perlman. 2006. The contested impact of cognitive linguistic research on the psycholinguistics of metaphor understanding. In Gitte Kristiansen, Michel Achard, René Dirven \& F. J. Ruiz de Mendoza (eds.), Cognitive Linguistics: Current applications and future perspectives, 211-228. Berlin \& New York: Mouton de Gruyter.

Grady, Joseph. 1997. Foundations of meaning: Primary metaphors and primary scenes. Berkeley: University of California PhD dissertation.

Grady, Joseph. 1999. A typology of motivation for conceptual metaphor: correlation vs. resemblance. In R. W. Jr. Gibbs, Raymond W. Jr. \& Gerard Steen (eds.), Metaphor in Cognitive Linguistics, 79-100. Amsterdam \& Philadelphia: John Benjamins.

Kimmel, Michael. 2005. Culture regained: Situated and compound image schemas. In Beate Hampe (ed.), From perception to meaning: Image schemas in Cognitive Linguistics, 285342. Berlin \& New York: Mouton de Gruyter.

Kövecses, Zoltan. 2002. Metaphor: A practical introduction. Oxford: Oxford University Press.

Kövecses, Zoltan. 2005. Metaphor in culture: Universality and variation. New York: Cambridge University Press.

Lakoff, George. 1987. Women, fire, and dangerous things. Chicago: University of Chicago.

Lakoff, George. 1990. The Invariance Hypothesis: Is abstract reason based on imageschemas? Cognitive Linguistics 1(1). 39-74.

Lakoff, George. 1993. The contemporary theory of metaphor. In A. Ortony (ed.), Metaphor and thought, 202-251. Cambridge: Cambridge University Press.

Lakoff, George \& Mark Johnson. 1980. Metaphors we live by. Chicago: University of Chicago Press.

Lakoff, George \& Mark Johnson. 1999. Philosophy in the flesh: The embodied mind and its challenge to Western thought. New York: Basic Books.

Lakoff, George \& Mark Turner. 1989. More than a cool reason: A field guide to poetic metaphor. Chicago: Chicago University Press.

Lima, Paula Lenz Costa. 2006. About primary metaphors. D.E.L.T.A. 22. 109-122.

Paivio, Alan. 1971. Imagery and verbal processes. New York: Holt, Rinehart and Winston.

Paivio, Alan. 1986. Mental representations: A dual coding approach. New York: Oxford University Press.

Popova, Yanna. 2005. Image schemas and verbal synaesthesia. In Beate Hampe (ed.), From perception to meaning: Image schemas in Cognitive Linguistics, 395-419. Berlin \& New York: Mouton de Gruyter.

Peña, María Sandra. 2003. Topology and cognition. What image-schemas reveal about the metaphorical language of emotions. Munich: Lincom Europa.

Peña, María Sandra. 1999. Subsidiarity relationships between image-schemas: An approach to the force schema. Journal of English Studies 1, 187-207.

Pylyshyn, Zenon. 2003. Return of the mental image: Are there really pictures in the brain? Trends in Cognitive Science 7(3). 113-118.

Radden, Günter. 2002. How metonymic are metaphors? In René Dirven \& Ralf Pörings (eds.), Metaphor and metonymy in comparison and constrast, 407-435. Berlin \& New York: Mouton de Gruyter.

Ruiz de Mendoza Ibáñez, Francisco \& María Sandra Peña Cervel. 2008. Grammatical metonymy within the 'action' frame in English and Spanish. In María de los Ángeles Gómez González, J. Lachlan Mackenzie \& Elsa M. González-Álvarez (eds), Current trends in contrastive linguistics: Functional and cognitive perspectives, 251-280. Amsterdam \& Philadelphia: John Benjamins. 
Rohrer, Tim. 2005. Image schemata in the brain. In Beate Hampe (ed.), From perception to meaning: Image schemas in Cognitive Linguistics, 165-196. Berlin \& New York: Mouton de Gruyter.

Talmy, Len. 1999. Fictive motion in language and "ception". In Paul Bloom, Mary A. Peterson, Lynn Nadel \& Merrill F. Garrett (eds.), Language and space, 211-276. Cambridge, MA: MIT Press.

Thomas, Nigel J. T. 1999. Are theories of imagery theories of imagination? An active perception approach to conscious mental content. Cognitive Science 23. 207-245.

Thomas, Nigel J. T. 2009. A note on "schema" and "image schema". http://www.imageryimagination.com/schemata.htm (accessed 20 May 2009).

Watt, Roger. 1991. Understanding vision. New York: Academic Press.

Weisberg, Robert. 1986. Creativity: Genius and other myths. New York: Freeman. 